\title{
Espaços de interação nas empresas: os lugares da comunicação formal face a face
}

Interaction spaces in business:

places for formal face to face communication

Espacios de interacción en las empresas:

los lugares de la comunicación formal cara a cara

\section{Kátia Perez}

- Mestre em Comunicação Social, com ênfase em Comunicação Interna, pela Universidade Metodista de São Paulo (Umesp)

- Especialista em Planejamento Estratégico em Comunicação pela Umesp

- Graduada em Comunicação Social - Jornalismo pela Umesp

- Consultora em comunicação organizacional, com foco em comunicação com empregados e publicações empresariais

- Integrante do grupo de pesquisa "Comunicação empresarial no Brasil: uma leitura crítica (Criticom)", da Umesp

- Capítulo publicado no livro Comunicação empresarial: planejamento e gestão, organizado por Wilson Bueno (2011)

- E-mail:katia.perez@outlook.com.br 


\section{Resumo}

Dentro das organizações, as áreas para o cafezinho, os refeitórios, as salas de reunião são pontos de encontro para interações. Esses locais, por si sós, têm um significado para os funcionários. Apesar disso, as organizações, atualmente, não têm aproveitado em sua totalidade esses espaços de interação em seus formatos de comunicação face a face. Esta é a principal reflexão proposta neste trabalho, que traz os resultados de uma pesquisa qualitativa realizada com representantes de catorze empresas, todos da área de comunicação corporativa.

PALAVRAS-CHAVE: COMUNICAÇÃO COM OS FUNCIONÁRIOS • ESPAÇOS DE INTERAÇÃO • COMUNICAÇÃO FORMAL FACE A FACE • PERIODICIDADE.

\section{Abstract}

In organizations, areas for coffee, dining halls and meeting rooms are places for interactions. These sites, by themselves, convey a meaning for employees. However, organizations do not fully leverage these interaction spaces as face to face communication channels. This is the main idea proposed in this article, which refers to the results of a qualitative research conducted with representatives of fourteen companies, all of them from the Corporate Communications area.

KEYWORDS: COMMUNICATION WITH EMPLOYEES • INTERACTION SPACES • FORMAL FACE TOFACE COMMUNICATION • PERIODICITY.

\section{Resumen}

Dentro de las organizaciones, las áreas de café, comedores, salas de reuniones son lugares para la interacción. Estos espacios, por sí mismos, tienen un significado para los empleados. No obstante, las organizaciones, actualmente, no han aprovechado estos espacios de interacción en sus formatos de comunicación cara a cara. Esta es la principal reflexión que se propone en este trabajo, después de realizar una investigación cualitativa llevada a cabo con representantes de catorze empresas, todos del ambiente de comunicación corporativa. 
orredores, refeitórios, máquina de café, bebedouros. Em qualquer organização, estes locais são especiais por serem os pontos de produção e disseminação da comunicação informal. Até mesmo um de seus apelidos - a rádio-corredor

- demonstra o local onde se dá esse tipo de comunicação: os corredores dos escritórios. 0 psicólogo e pesquisador Nicholas DiFonzo, profundo conhecedor dos boatos organizacionais, faz referência à importância desses locais no título de um de seus livros: The watercooler effect:

Outro dia, perguntei à minha esposa se ela tinha um bebedouro em seu escritório. "Chama-se cafeteira", ela respondeu. Ela entendera perfeitamente minha pergunta. Eu queria saber sobre o local onde as pessoas costumam se encontrar, onde os boatos tendem a se espalhar (DiFonzo, 2008, p. 1).

É dessa forma que Nicholas DiFonzo inicia o primeiro capítulo do livro mencionado. Ele coloca como ponto de partida para alguns de seus estudos sobre os boatos, inclusive os boatos organizacionais, o lugar onde as pessoas se reúnem para interagir, trocar informações e disseminar o conteúdo do 'noticiário' informal. E, também, a forma como esse local é visto e interpretado pelas pessoas que trabalham e convivem na empresa: subentende-se que é o ponto de encontro para aqueles que buscam informações.

Se os lugares/cenários, por si sós, já carregam essa dose de informação, o que poderíamos dizer dos locais onde acontece a comunicação formal face a face? As organizações possuem seus lugares específicos para a disseminação de informações, mas esses locais são efetivamente usados para fomentar o diálogo entre administração e funcionários? Afinal, como as empresas usam (ou não) seus espaços de interação/convivência nos formatos face a face de comunicação formal?

Tentando colocar um pouco de luz sobre essas questões, e também com o objetivo de contribuir para a construção de uma prática mais participativa na comunicação formal dentro das organizações, trazemos algumas reflexões, baseadas em breve revisão bibliográfica e pesquisa qualitativa exploratória, realizada entre janeiro e março de 2013. Para a coleta desses dados foram utilizados questionários semiabertos, disponibilizados online, e respondidos voluntariamente por catorze profissionais de comunicação corporativa de empresas diversas.

\section{DIÁLOGO FORMAL}

A comunicação é um processo natural dentro das organizações. Todos os funcionários, nos diversos níveis hierárquicos, comunicam-se a cada momento, seja pessoalmente ou com a ajuda de um meio, eletrônico ou não. Essa comunicação dentro das organizações é definida por Wilson Bueno (2008, on-line) como "o processo de relacionamento de uma organização com os seus públicos internos e dos públicos internos entre si"2. E é nessa primeira frase - o processo de relacionamento de uma organização com os seus públicos internos - que encontramos um fragmento do conceito de comunicação formal, relevante para este nosso estudo.

Podemos acrescentar que toda organização, representada pela cúpula administrativa, tem necessidade de criar veículos para se comunicar, de forma que a 'máquina corporativa' tenha um bom funcionamento. Esses canais e as mensagens são preparados por uma equipe de funcionários, de 'gerenciadores' da informação. É o que Margarida Kunsch (2003, p. 154) chama de "comunicação interna",

1 Literalmente, "O efeito bebedouro". A obra foi traduzida, no Brasil, como 0 poder dos boatos.

2 Curso online "Comunicação interna", da Comtexto Comunicação e Pesquisa, ministrado pelo Prof. Dr. Wilson da Costa Bueno e do qual a autora participou no 1ำ semestre de 2008. 
um setor planejado, com objetivos bem definidos, para viabilizar toda a interação possível entre a organização e seus empregados, usando ferramentas da comunicação institucional e até da comunicação mercadológica (para o caso do endomarketing ou marketing interno).

Pensar a mensagem, seus conteúdos, formatos e distribuição mostra que essas informações passam por um processo cuidadoso antes de chegar aos públicos internos. E, portanto, não são espontâneas ou informais. A comunicação formal está presente nas organizações, como explica Giselle Grando (2008, p. 228), "para que todas as instâncias mantenham o foco nos objetivos e metas, desempenhando suas tarefas e papéis conscientes da missão e imbuídos da filosofia da organização".

Na atualidade, as organizações estão diante de um leque de possibilidades para manter a comunicação com seus funcionários. Mas neste mundo recheado de tecnologia e mediações, observamos que a comunicação formal face a face, presencial, vem sendo valorizada no mundo dos negócios. E Marlene Marchiori (2008, p. 217) cita algumas características desse formato:

A comunicação face a face é ágil, permite interação e tem credibilidade, devendo ser valorizada pelos profissionais. Os veículos de comunicação podem completar e apoiar o processo. Parece que estamos nos direcionando para a seguinte perspectiva de atuação: informação, interação, relacionamento, conhecimento e validação das relações fundamentando um processo de comunicação interna que constrói credibilidade.

Essas interações exigem, muito mais que os outros formatos de comunicação, um ambiente para sua realização. E um ambiente propício, conforme veremos.

\section{LOCAIS E SUAS MENSAGENS}

As salas de reuniões, os auditórios ou as áreas de convivências (existentes até no coração da produção, nas fábricas) são uma realidade do mundo empresarial da atualidade. E, assim como na comunicação informal, conforme mostramos no início deste artigo, esses espaços carregam um significado especial para os seus frequentadores. A reunião ou o encontro de funcionários em determinado local dentro da empresa, específico para a interação (especialmente entre os representantes da administração da empresa e as demais equipes de trabalho) já faz com que o funcionário subentenda uma mensagem. Jacques Girin (2008, p. 48) conceitua que

uma situação é definida por três aspectos: pelos participantes da situação, por uma dimensão espacial (o local ou os locais em que ela se desenrola, os objetos materiais que aí se encontram) e por uma dimensão temporal (um começo, um fim, um desenvolvimento e, eventualmente, uma periodicidade).

Esses elementos de uma situação - e gostaríamos de ressaltar o local e a periodicidade - fornecem indícios para que as pessoas utilizem suas experiências anteriores para interpretar e compreender aquela nova ocorrência, os acontecimentos do momento (Girin, 2008, p. 58-59). E o autor ainda fornece um exemplo de situação, bastante corriqueiro no mundo corporativo:

Se meu patrão, com quem acabei de ter uma conversa amigável alguns minutos atrás, me chama repentinamente a seu escritório, devo me preparar para interpretar o que ele vai me dizer em um contexto de autoridade (ele vai dar alguma coisa urgente para eu fazer, ou acaba de encontrar um motivo para me repreender); é possível também que eu deva usar um contexto de racionalidade (ele precisa da minha opinião especializada) e, provavelmente, não deverei fazer nenhuma interpretação em um contexto de relações (Girin, 2008, p. 61). 
Ou seja, nessa situação, o local - a sala do chefe - já faz parte da mensagem. Podemos inferir que o local ajudou o funcionário a perceber que a comunicação que receberia era importante por ocorrer em um local determinado. Desse modo, 0 ato de promover um encontro entre funcionários, com a intenção de incentivar o diálogo entre diferentes níveis hierárquicos da organização ou de repassar informações formais, em um local preparado e previamente determinado, com horários previstos (inclusive observando-se a periodicidade desses encontros), já envia uma mensagem específica aos participantes, remetendo a situações comunicacionais, sejam estas positivas ou não.

Descrevendo e orientando trabalhos de inserir e alimentar uma cultura de diálogo nas organizações, as pesquisadoras Linda Ellinor e Glenna Gerard (2008, p. 274) recomendam que, para "nutrir o diálogo nas organizações", é preciso que se "crie um espaço físico destacado para o diálogo".

A ideia é que as pessoas lembrem umas às outras que o diálogo não é a maneira comum pela qual sempre falamos. (...) Uma das maneiras de se manter a distinção é criar um ambiente físico diferente para estabelecer diálogos. Uma empresa que conhecemos criou uma sala de diálogo.

Esse local apropriado para as interações formais, juntamente com a periodicidade, farão com que os funcionários interpretem o encontro como uma forma de receber informações relativas à organização. Ellinor e Gerard ainda fazem uma advertência no que se refere à periodicidade: se esta não for respeitada, haverá uma desmotivação dos funcionários. Com isso, entendemos que os encontros podem perder seu valor e, até mesmo, cair em descrédito.

Ter um gostinho do poder do diálogo e depois vê-lo ser retirado pode ser frustrante e desestimulante. Poderíamos comparar isso a dirigir um carro turbo por uma semana e depois voltar para um fusquinha. Mas é pior, porque o que foi perdido é mais importante do que dirigir em alta velocidade; é a possibilidade de uma vida profissional de melhor qualidade (Ellinor; Gerard, 2008, p. 277).

Além dessas questões que envolvem espaço e tempo, é necessário salientar algumas informações sobre a percepção dos funcionários ante a comunicação formal face a face. Apesar de vivermos num cenário onde as interações mediadas parecem ter invadido as culturas organizacionais, pesquisas recentes (e aqui ressaltaremos duas delas) mostram que os funcionários preferem os formatos face a face de comunicação, se não na totalidade, certamente em algumas situações específicas vividas pelas organizações.

\section{MENSAGENS FACE A FACE}

A pesquisadora Lee Cheng Ean, cujo trabalho teve seus resultados publicados em 2010, conduziu um estudo em cinco organizações da Malásia para comparar a efetividade das comunicações face a face e das mediadas por computador, entre os funcionários. Para isso, ela realizou quinze entrevistas em profundidade com gestores de comunicação de empresas de pequeno e médio porte. De acordo com a pesquisadora, embora a comunicação eletrônica seja mais frequentemente usada, a comunicação face a face é a preferida pelos funcionários, sendo mais efetiva para a construção de relacionamentos com gestores e disseminação de informações relativa ao trabalho.

Quando os entrevistados foram questionados sobre o canal de comunicação preferido pelos funcionários, a maioria deles citou a comunicação face a face, devido a vantagens como: respostas diretas, comunicação de duas vias, múltiplas informações simbólicas, além de boa para construir relacionamentos e colaboração em projetos (Ean, 2010, p. 45)³.

3 Tradução nossa. 
Em outro estudo, desta vez realizado nos Estados Unidos, em 2006, as pesquisadoras Zinta Byrne e Elaine LeMay foram a campo para investigar a percepção dos funcionários, em especial sua satisfação, em relação aos tipos de comunicação disponibilizados na empresa. Recorrendo à teoria da riqueza dos meios de comunicação ${ }^{4}$, que postula que a "informação pode ser interpretada diferentemente, dependendo do meio/veículo com o qual ela é transmitida" (Byrne; Lemay, 2006, p. 154), elas agruparam os formatos de comunicação formal existentes nas organizações em três grupos: ricos, moderados e enxutos.

Especificamente, Daft e Lengel (1984) sugerem que pelo fato de a comunicação face a face incluir linguagem corporal, expressões faciais e tons de voz, que podem ser observados ao mesmo tempo, ela carrega mais informação. Em contraste, faltam essas características nas mensagens escritas, resultando em menos informação processada pelo receptor e, portanto, mensagens escritas são consideradas menos ricas do que a comunicação face a face (Byrne; Lemay, 2006, p. 154)5.

Para o nosso estudo, destacamos aqui apenas os formatos de comunicação mais ricos e os menos ricos (ou enxutos). Para Zinta Byrne e Elaine Lemay, os meios de comunicação ricos nas organizações, e que permitem uma interação entre os participantes, são: reunião entre chefe e subordinado, conversas ao telefone e reuniões de departamento. Já os meios de comunicação menos ricos, e que não possibilitam interações, foram considerados: newsletter, mensagens escritas, reuniões gerais de escritório/fábrica e reuniões gerais trimestrais da companhia (Byrne; Lemay, 2006, p. 160).

Ao término de sua pesquisa, depois de entrevistarem 598 funcionários de uma empresa do oeste norte-americano, elas concluíram que os funcionários obtêm mais satisfação das comunicações vindas por meios ricos quando o assunto se refere ao trabalho pessoal. Da mesma forma, a comunicação formal face a face (em conversas individuais ou reuniões de departamento) e as comunicações via telefone geram maior satisfação ao funcionário quando 0 assunto comunicado se refere à sua unidade de negócios ou que terá efeito direto em seu trabalho. Quando a informação é sobre a empresa e tem uma amplitude maior, os funcionários preferem que a comunicação venha por meios menos ricos, como os formatos escritos ou as reuniões gerais que envolvem todos os funcionários da companhia. "Quando a informação recebida não é diretamente relevante para eles, os funcionários não precisam de dados adicionais fornecidos por sinais visuais, como expressões faciais, para ficarem satisfeitos" (Byrne; Lemay, 2006, p. 166) ${ }^{6}$.

Conforme podemos observar, tanto a comunicação formal face a face como os locais onde essas interações acontecem interferem diretamente na eficácia da comunicação, na vida profissional dos funcionários. Agora, podemos perguntar: e como andam nas empresas brasileiras os formatos de comunicação face a face, disponibilizados e elaborados por elas para se relacionarem com seus públicos internos?

Para fornecer uma base sobre essa questão, recorremos à Associação Brasileira de Comunicação Empresarial (Aberje), que periodicamente divulga um trabalho essencial para que pesquisadores e profissionais da área de comunicação corporativa visualizem mais profundamente o perfil da comunicação realizada com seus públicos internos. Em 2012, já em sua quarta edição, a Pesquisa de Comunicação Interna da Aberje coletou dados de 179 empresas associadas à entidade e mostrou que a comunicação face a face está disponível para os funcionários em 68,7\% delas (Aberje, 2012). Esse formato de comunicação ainda foi apontado como o principal veículo de comunicação em 4,2\% das empresas entrevistadas.

4 Ver: Daft; Lengel, 1984

5 Tradução nossa.

6 Tradução nossa. 
Entre os canais de comunicação dirigidos apenas para os executivos, 18,6\% dos entrevistados afirmam que a comunicação formal face a face é o principal, ficando atrás apenas dos comunicados por e-mails (44,1\%). Conforme avaliação da pesquisa, a comunicação face a face registrou crescimento significativo como formato destinado a esse público específico, pois em sua edição anterior, em 2007, apenas 3,7 das comunicações a executivos eram feitas por formatos face a face de comunicação formal (Aberje, 2012, p. 16). Estatisticamente, a comunicação face a face está presente nas empresas. Falta observar se ela realmente cumpre seu papel.

\section{FACE A FACE COM OS PÚBLICOS INTERNOS}

O objetivo deste estudo foi traçar os primeiros contornos de um mapa que nos mostre como as empresas estão trabalhando os espaços destinados à comunicação face a face. Para isso, o primeiro passo foi recolher dados de empresas sobre a prática da comunicação face a face e saber se e quais espaços de interação existem no ambiente organizacional e como são usados.

Valendo-nos de grupos de discussão sobre comunicação interna nas empresas existentes na rede social Linkedin, foi disponibilizado um convite para participação na pesquisa, bem como o link para um questionário online. A pesquisa foi respondida voluntariamente por catorze representantes de empresas que atuam na área de comunicação corporativa. A presença de questões semiabertas permitiu aos respondentes registrar suas próprias experiências (embora não tenha sido face a face, este foi nosso espaço de interação). Dos respondentes, nove estão no estado de São Paulo, três no Rio de Janeiro, uma na Bahia e uma no Distrito Federal. Como o objetivo do trabalho era, num primeiro momento, conhecer os espaços de interação e sua utilização pela comunicação formal face a face, não foi considerado o porte da empresa nesta avaliação. Para divulgar os dados coletados, a seguir organizamos o material em algumas subdivisões que facilitarão as reflexões a serem propostas posteriormente.

\section{Ambientes de interação}

Buscando conhecer quais os espaços disponíveis nas empresas, apropriados para a prática das interações face a face, elencamos uma série de opções possíveis, acrescentando espaço para comentários dos respondentes. As salas de reuniões estão presentes na quase totalidade das empresas analisadas, registrando uma exceção (empresa 11). Restaurantes/ refeitórios são ambientes existentes em sete dentre as catorze pesquisadas (empresas 3, 6, 8, 9, 10, 11 e 12), sendo que 0 representante da empresa 13 ressaltou a existência de uma cafeteria. Quase metade das empresas avaliadas possui auditório: seis (empresas 5, 6, 9, 10, 11, 12). E, finalmente, quatro dos respondentes declararam que as empresas onde trabalham têm espaços de lazer: empresa 6 (espaço para ginástica laboral e alongamento); empresa 14 (espaço para massagens, denominado "Mais vida"); a empresa 9 e a empresa 11 não especificaram como seriam esses espaços nem sua finalidade.

Os comentários feitos pelos representantes das empresas 7 e 8 merecem ser registrados aqui, pois eles afirmaram que, embora as empresas possuam salas de reunião, estas não são usadas para encontros ou interações. Empresa 7: "Existem salas de reunião, mas não são usadas para interações, não para esses tipos de eventos." Empresa 8: "Não são usadas para esse tipo de evento, mas para treinamentos, reuniões e datas comemorativas." 


\section{Formatos face a face de comunicação formal}

No que se refere a veículos de comunicação face a face, elaborados pelas equipes de comunicação corporativa, seis dos respondentes afirmaram possuir um formato de conversa entre chefes e subordinados (empresas 3, 6, 8, 11, 13, 14); seis deles assinalaram o formato de encontros/eventos (empresa 4, 6, 9, 11, 12, 14); e cinco disseram possuir um formato de café com o presidente (empresas 4, 6, 7, 10, 11).

Logo após a questão sobre os formatos de comunicação face a face existentes na empresa, foi colocada a seguinte questão aberta: "Em sua opinião, qual o veículo de comunicação mais eficiente para a empresa onde trabalha?" Apenas três respostas fizeram referência à comunicação formal face a face: encontros (empresa 6), comunicação face a face (empresa 13) e encontros/newsletter (empresa 14).

Vale registrar o comentário feito pelo respondente da empresa 6 para essa questão: "Precisa do mix de comunicação, sempre, pois cada área e cada pessoa tem seu perfil. Mas os encontros são sempre mais importantes, embora a periodicidade seja menor que a das demais ferramentas." Tal empresa mostra que utiliza a comunicação formal face a face, abrindo um leque de possibilidades de interação. No espaço para relato de experiência, o representante da empresa 6 fez o seguinte detalhamento: "Temos o café da manhã com o diretor: bimestral. Mingau com o gerente (pela manhã ele vai à área comercial e faz um bate-papo informal durante um mingau, mensalmente). Reunião de segurança mensal com todos os lideres (ADM e manufatura), reunião de segurança mensal com as contratadas que atuam diariamente na fábrica. Reunião trimestral para apresentação do negócio (no auditório, com todos). Semestralmente é feita uma rodada de cinco reuniões, todas com os mesmos temas, sendo uma envolvendo cada turno de trabalho, com o objetivo de envolver todos os trabalhadores. Os assuntos são variados, com objetivos de alinhar informações das mais diversas áreas".

Já o representante da empresa 7, que apontou como principal veículo a newsletter, afirmou: "Nenhum é realmente eficiente. 0 que é mais abrangente é a newsletter, mas não temos (ainda) garantia de que todos os funcionários recebem as informações". Apenas para lembrar, essa empresa possui, como um de seus veículos formais de comunicação, o café da manhã com presidente.

\section{Periodicidade}

No que se refere à periodicidade das interações, quatro respondentes afirmaram que os gestores fazem reuniões periódicas com os funcionários, para repasse de informações ou troca de ideias apenas em momentos de criseou conformea necessidade (empresas 3, 9, 10 e 13). 0 respondente da empresa 5 assinalou que esses encontros nunca acontecem, enquanto na empresa 4 eles são anuais e na empresa 14, semestrais.

No restante das empresas - sete delas, ou seja, a metade das entrevistadas -, as interações superior imediato/funcionários são mais frequentes: mensais (empresas 7, 8 e 11), e(Empresas 1 e 12) e diárias (empresas 2 e 6). Vale observar o complemento feito pelo respondente da empresa 6: "Depende do perfil da reunião: Segurança é diária, com a equipe, e mensal, com lideranças. Situação do negócio é trimestral. Produção é diária. Temas gerais, sempre que necessários". 


\section{Equipe de comunicação interna}

De todas as pesquisadas, apenas a empresa 5 não possui uma equipe de comunicação interna formalizada e também não tem formatos de comunicação face a face. Apesar disso, a equipe de comunicação corporativa é responsável por produzir e manter ativa a intranet, a newsletter e o jornal mural.

As demais empresas, conforme seus representantes afirmaram, possuem equipes de comunicação interna, com funcionários contratados. Mas alguns comentários registrados mostraram as dificuldades enfrentadas pelas equipes dentro das empresas. 0 representante da empresa 8 afirmou: "A comunicação interna é uma área que a cada dia se torna mais importante e indispensável nas organizações, porém poucas destas agem com tal clareza e conhecimento." Essa mesma dificuldade é compartilhada pelo representante da empresa 3: "A comunicação interna está começando comigo, que fui contratada há pouco mais de um ano. Estou batalhando para a área ser reconhecida (...) e tentando implantar um jornal e revitalizar o mural".

E também há as dificuldades para a adequação de veículos de comunicação a públicos internos. Um desses casos foi relatado pelo representante da empresa 9: "Já tivemos uma rádio dentro da empresa, mas não funcionou, porque os colaboradores da companhia queria apenas músicas e não queriam ouvir nada de informação. Houve até um abaixo-assinado para tirar a rádio do ar ou deixar uma rádio da região". Na empresa 10, sua representante explicou que "a intranet é nova na empresa, ainda não é um canal consolidado. A newsletter (comunicado interno), apesar de ser importante, é usado com excessiva frequência", sendo mesmo supervalorizada, em detrimento de outros canais de comunicação.

\section{CONSIDERAÇÕES FINAIS}

Ao concluir a organização dos dados coletados, propomos uma reflexão a partir das respostas obtidas dos catorze representantes que atuam nas equipes de comunicação corporativa das empresas participantes da pesquisa. Nossa intenção não é - e nem foi, ao levantarmos o problema inicial - generalizar os resultados ou obter uma "cura" para nossas mazelas comunicacionais e organizacionais. Mas toda transmissão de dados sem a devida discussão é comparável ao evento face a face entre diretoria e funcionários sem a rodada de perguntas e respostas ao final.

Observando as informações recebidas, entendemos que as empresas, na atualidade, não estão totalmente destituídas de espaços para interações face a face. Pelo contrário. Além das tradicionais salas de reuniões, há auditórios, restaurantes/ refeitórios, cafeterias (como enfatizou o representante da empresa 13) e até locais destinados ao lazer, conforme resposta de quatro das catorze empresas respondentes. São espaços que transferem os funcionários para fora de seus postos de trabalho diário e podem remetê-los a um ambiente diferenciado, incentivador do diálogo, motivacional. Ou, ao menos, propício a um repasse de informações que utilize o cenário como parte de um sentimento de pertencimento, um envolvimento emocional e inovador entre a organização (vista, aqui, como marca, como instituição) e as pessoas que fazem parte dela.

Apesar de encontrarmos esses espaços de interação, percebemos que as empresas respondentes não aproveitam esses locais - em sua gama de possibilidades - para fomentar encontros entre cúpula administrativa e funcionários. 0 formato face a face de comunicação formal, embora usado em onze das empresas respondentes, foi observado como o veículo mais importante em três delas. Mas, entre elas, apenas uma, a empresa 6, faz encontros regulares, periódicos e envolvendo vários departamentos da empresa, bem como gestores de todos os níveis e funcionários. 
De acordo com os dados apresentados, a empresa 13 apontou a comunicação face a face como mais eficiente, mas seu único formato de interação - conversa entre chefe e subordinados - acontece apenas em momentos de crise. Na empresa 14, cujo representante citou os encontros como o mais eficiente dos veículos de comunicação, eles apenas acontecem semestralmente. Ou seja, os espaços não estão sendo usados com sabedoria e nem mesmo os formatos de comunicação face a face, comprometendo o fluxo de comunicação (ou de informação) entre administração das empresas e corpo de funcionários.

Esta questão da periodicidade dos encontros face a face entre gestores e suas equipes também nos forneceu informações sobre a consistência dessas interações. Metade dos participantes da pesquisa revelou que os encontros face a face acontecem ou em momentos de crise ou de acordo com a necessidade ou muito distantes uns dos outros, o que compromete o fluxo aceitável de comunicação dentro de uma organização. Mas também encontramos a outra metade, que já planeja encontros mensais, semanais e até diários, o que é sinal de que o diálogo está se tornando um hábito.

Se a política de comunicação das empresas valoriza o diálogo nas organizações, a questão da periodicidade é essencial para o seu bom funcionamento. E, se ainda não podemos afirmar a valorização dessa cultura comunicacional, entendemos que já existe uma preocupação. Mesmo que timidamente, essa preocupação com a comunicação dentro das empresas já pode ser notada devido à presença de equipes chamadas de comunicação interna: das catorze empresas respondentes, treze possuem pessoas direcionadas para a comunicação interna.

As dificuldades ainda são grandes e o trabalho é imenso, conforme declararam alguns dos respondentes. Mas a presença de uma pessoa contratada, para pensar a comunicação com os funcionários, significa alguma coisa.

São tempos de desafio, para nós que estudamos, pesquisamos e atuamos nas equipes de comunicação com os funcionários, dentro das organizações. Mas temos a possibilidade de refletirmos, juntos, questões como a importância dos locais onde ocorrem as interações face a face e de que modo a construção desses cenários, com uma periodicidade adequada e o formato face a face ideal para os públicos, pode motivar funcionários, incentivar o diálogo, estreitar laços e, desse modo, enriquecer 0 ambiente organizacional.

\section{REFERENNCIAS}

ABERJE. Associação Brasileira de Comunicação Empresarial. 4ª̣ pesquisa de comunicação interna-2012. São Paulo: Aberje Editorial, 2012. Mensagem recebida por <katia.perez@ig.com.br> em 17 abr. 2008.

BUENO, Wilson da Costa (Org). Comunicação empresarial: planejamento e gestão. São Paulo: All Print Editora, 2011.

BYRNE, Zinta S.; LEMAY, Elaine. Different media for organizational communication: perceptions of quality and satisfaction. Journal of Business and Psychology, v. 21, n. 2, p. 149-173, 2006. Disponível em: <http://www.jstor.org/stable/25092963> Acesso em: 01 ago. 2013.

DAFT, Richard L.; LENGEL, Robert H. Information richness: a new approach to managerial behavior and organizational design. In: CUMMINGS, Larry L.; STAW, Barry M. (Eds.). Research in organizational behavior. Homewood, IL: JAI Press, 1984. p. 191-233. Disponível em: <http://www.dtic.mil/dtic/tr/fulltext/u2/a128980.pdf>. Último acesso em: 01 ago. 2013. 
DIFONZO, Nicholas. O poder dos boatos. Rio de Janeiro: Elsevier, 2009.

EAN, Lee Cheng. Face-to-face versus computer-mediated communication: exploring employees' preference of effective employee communication channel. International Journal for the Advancement of Science \& Arts, Selangor D.E. (Malaysia), School of Communication, Taylor's University Malaysia, v. 1, n. 2, p. 38-48, 2010. Disponível em: <http://www.academia. edu/538403/Face-to-face_Versus_Computer-mediated_Communication_Exploring_Employees_Preference_of_ Effective_Employee_Communication_Channel>. Acesso em: 19 jul. 2013.

ELLINOR, Linda; GERARD, Glenna. Diálogo: redescobrindo o poder transformador da conversa. São Paulo: Futura, 1998.

GIRIN, Jacques. A linguagem nas organizações; signos e símbolos. In: CHANLAT, Jean-François (Coord.). 0 indivíduo na organização: dimensões esquecidas. Vol. 3. São Paulo: Atlas, 2008. p. 23-65.

GRANDO, Giselle B. Redes formais e informais por um diálogo interno mais eficaz. In: MARCHIORI, Marlene (Org.). Faces da cultura e da comunicação organizacional. São Caetano do Sul, SP: Difusão Editora, 2008.

KUNSCH, Margarida M. Krohling. Planejamento de relações públicas na comunicação integrada. 4. ed. - rev. e ampl. São Paulo: Summus, 2003.

MARCHIORI, Marlene. Comunicação interna: um fator estratégico no sucesso dos negócios. In: MARCHIORI, Marlene (Org.). Faces da cultura e da comunicação organizacional. São Caetano do Sul, SP: Difusão Editora, 2008.

PEREZ, Katia. Rádio-peão no ar. um estudo sobre a comunicação face a face no ambiente organizacional. In: BUENO, Wilson da Costa (Org). Comunicação empresarial: planejamento e gestão. São Paulo: All Print Editora, 2011. p. 39-54.

Artigo recebido em 29.08.2013 e aprovado em 21.11.2013. 